\title{
Circumspective
}

\section{Ketamine: Promising Path or False Prophecy in the Development of Novel Therapeutics for Mood Disorders?}

\author{
Gerard Sanacora*,' and Alan F Schatzberg ${ }^{2}$ \\ 'Yale University School of Medicine, New Haven, CT, USA; ${ }^{2}$ Stanford University School of Medicine, Stanford, CA, USA
}

\begin{abstract}
Large 'real world' studies demonstrating the limited effectiveness and slow onset of clinical response associated with our existing antidepressant medications has highlighted the need for the development of new therapeutic strategies for major depression and other mood disorders. Yet, despite intense research efforts, the field has had little success in developing antidepressant treatments with fundamentally novel mechanisms of action over the past six decades, leaving the field wary and skeptical about any new developments. However, a series of relatively small proof-of-concept studies conducted over the last 15 years has gradually gained great interest by providing strong evidence that a unique, rapid onset of sustained, but still temporally limited, antidepressant effects can be achieved with a single administration of ketamine. We are now left with several questions regarding the true clinical meaningfulness of the findings and the mechanisms underlying the antidepressant action. In this Circumspectives piece, Dr Sanacora and Dr Schatzberg share their opinions on these issues and discuss paths to move the field forward.
\end{abstract}

Neuropsychopharmacology (2015) 40, 259-267; doi:10.1038/npp.20I4.26I; published online 22 October 2014

\section{NMDA ANTAGONISM AND MODULATION OF GLUTAMATE NEUROTRANSMISSION ARE KEY MECHANISMS UNDERLYING KETAMINE'S ANTIDE- PRESSANT ACTIONS (GERARD SANACORA)}

\section{"Our brightest blazes of gladness are commonly} kindled by unexpected sparks."

\section{Samuel Johnson, The Idler; Poems}

There is little disagreement over the need for improved antidepressant therapeutics, yet in recent years, the pharmaceutical industry has been abandoning this therapeutic area at an alarming rate. The discovery of ketamine's rapid antidepressant effects has reinvigorated the field and revolutionized our thinking about antidepressant medications in several respects. First, ketamine's ability to induce a rapid onset of antidepressant and anxiolytic effects demonstrates that it is not necessary to wait weeks to achieve a clinically meaningful level of improvement. Second, ketamine has proven effective in patients who were highly resistant to the existing armamentarium of antidepressant medications, thus suggesting that it may also address the problem of 'treatment resistant depression'. Finally, ketamine appears to work via a unique mechanism of action

\footnotetext{
*Correspondence: Dr G Sanacora, Yale University School of Medicine, Clinical Neuroscience Research Unit, 34 Park Street, New Haven, CT 065 I9, USA, Tel: +203974 7535, Fax: +203974 7662,

E-mail: gerard.sanacora@yale.edu

Received 30 July 2014; revised II September 2014; accepted 13 September 2014; accepted article preview online 26 September 2014
}

(MoA), not directly targeting the monoaminergic neurotransmitter systems, suggesting that it is possible to develop novel classes of antidepressants with unique targets of engagement. Understanding the true clinical utility of this novel treatment approach and identifying the mechanisms mediating ketamine's antidepressant effects have become a focus of many researchers and pharmaceutical companies, and serves as the motivation for this perspective.

\section{NMDA Antagonism as a Target for Antidepressant Drug Development}

There is now incontrovertible evidence that a single administration of ketamine is associated with a transient improvement in depressive symptoms lasting for several days (Aan Het Rot et al, 2012; McGirr et al, 2014). However, the mechanisms underlying this effect remain unclear. Conventional wisdom suggests that ketamine's effects are mediated through actions on the glutamatergic $N$-methyl-Daspartate receptor (NMDAR). Although ketamine has been shown to have effects on several neurotransmitter and neuromodulatory systems (see Dr Schatzberg's section), the majority of ketamine's known pharmacological effects are mediated through the NMDAR (Anis et al, 1983; Bergman, 1999), where it acts as an open channel, noncompetitive antagonist, binding within the ion channel and blocking ion influx (Sinner and Graf, 2008; Thomson et al, 1985). Over two decades ago, Skolnick and collaborators initially speculated that a dampening of NMDAR function could be a common mechanism underlying antidepressant efficacy. This was based on observations that chronic treatment with various classes of antidepressant agents impacted NMDAR 
function (Nowak et al, 1993; Paul et al, 1993), and reports of abnormal NMDAR binding in the brains of suicide victims (Nowak et al, 1995), and rodents subjected to chronic stress conditions (Nowak et al, 1998; see Pilc et al (2013); Skolnick (1999) for reviews). However, the strongest evidence that actions at the NMDAR are mediating the antidepressant effects of ketamine comes from the fact that other drugs with NMDAR antagonist properties also show antidepressant-like effects. Several drugs that effectively either block or antagonize NMDAR activity, such as the competitive NMDAR antagonists CGP 37849 and CGP 40116 (Papp and Moryl, 1994), the noncompetitive, non-subunit selective NMDAR antagonist MK-801 (Autry et al, 2011; Lima-Ojeda et al, 2013; Maeng et al, 2008), and the NR2B selective antagonist RO-25-6981 (Li et al, 2010; Lima-Ojeda et al, 2013; Maeng et al, 2008), have repeatedly and fairly consistently been shown to have antidepressant-like properties in rodent models; although, possible differences in the onset and duration of the antidepressant-like effect have been observed.

There is also emerging evidence from clinical trials. A relatively small clinical trial suggested that the NR2B selective drug, CP-101606, led to robust, sustained antidepressant effects in SSRI non-responders (Preskorn et al, 2008). Two small proof-of-concept studies with AZD6765 (lanicemine), a nonselective, low trapping NMDAR-blocking drug suggest that a single infusion can have rapid but short-lived antidepressant effects above the relatively strong effect of a placebo (saline) infusion, in the absence of appreciable psychotomimetic effects (Sanacora et al, 2013; Zarate et al, 2013). A third, larger phase IIb study examining the adjunctive use of repeated lanicemine infusions (three infusions/week for 3 weeks), provided strong evidence of the drug's antidepressant efficacy and showed that the response could be maintained for a period of weeks (Sanacora et al, 2013). A recently completed follow-up study exploring the longer-term efficacy of lanicemine was unable to replicate the findings of clinical efficacy (Sanacora et al, 2014). However, this study met with the field's age-old problem; placebo administration produced a $39 \%$ response rate at the primary endpoint of 6 weeks. The issue of high placebo response rates has become an increasingly problematic obstacle in the meaningful evaluation of clinical trials in major depressive disorder (Iovieno and Papakostas, 2012). It would not be surprising if this same issue complicates the evaluation of these novel rapid-acting antidepressant medications, especially if the randomization blind can be adequately maintained.

Overall, the combined data from preclinical and clinical studies using a variety of different NMDAR modulating drugs provide generally consistent evidence that antidepressant effects are associated with NMDAR antagonism, and that this is probably the primary mechanism through which ketamine is generating its antidepressant effects. The fact that memantine, an NMDAR antagonist that shares many pharmacodynamic features with ketamine (Emnett et al, 2013), has not been consistently shown to have antidepressant effects (Smith et al, 2013; Zarate et al, 2006b) has been used to argue against the role of the NMDAR in mediating the antidepressant effects of ketamine. However, it is important to note that there are several differences in the way these molecules functionally interact with the receptor. For example, memantine does not inhibit the phosphorylation of eukaryotic elongation factor 2 (eEF2), nor does it augment subsequent expression of brain-derived neurotrophic factor (BDNF), which appear to be critical determinants of ketamine-mediated antidepressant efficacy (Gideons et al, 2014, see below). These differential effects could be related to relative differences in the drugs' abilities to change glutamate binding at rest (Gideons et al, 2014), differing trapping properties of the drugs (Kotermanski et al, 2009), or to uniquely different effects on synaptic and extrasynaptic receptors (Hardingham and Bading, 2010; Parsons and Raymond, 2014; Zhou et al, 2013).

\section{Modulation of Glutamate Neurotransmission as a Target for Antidepressant Drug Development}

\begin{abstract}
"There's no limit to how complicated things can get, on account of one thing always leading to another."
\end{abstract}

\section{E.B. White}

The simple fact that ketamine's antidepressant effects grow in magnitude after the drug has cleared from the body indicates that more durable downstream effects, beyond immediate blocking of the NMDAR, are critical in generating and sustaining the response. A rapidly expanding series of studies suggest that ketamine-induced enhancement of spine-remodeling and synaptoplasticity are critical in generating the sustained antidepressant effects (see Figure 1 for model overview). These effects appear dependent on a transient increase in glutamate transmission through the postsynaptic $\alpha$-amino-3-hydroxy-5-methyl-4-isoxazolepropionic acid receptors (AMPAR), as the co-administration of AMPAR antagonists can block the antidepressant effect of ketamine and other NMDAR antagonists in animal models (Autry et al, 2011; Duman and Aghajanian, 2012; Koike et al, 2011; Maeng et al, 2008). Studies showing the dose dependence of ketamine's activation of the mammalian target of rapamycin complex1 (mTORC1) signaling pathway, synaptic protein synthesis and antidepressantlike behaviors, parallel ketamine's dose-dependent effects on glutamate efflux as determined by microdialysis (Moghaddam et al, 1997) and ${ }^{13} \mathrm{C}-\mathrm{MRS}$ (Chowdhury et al, 2012) suggest that the transient increase in glutamate release may be a key proximal event in the cascade. Other studies showing $\mathrm{mGluR}_{2 / 3}$ antagonists, that also lead to an increased release of presynaptic glutamate, produce ketamine-like biochemical and behavioral effects which are blocked by AMPA receptor blockade (Dwyer et al, 2012; Karasawa et al, 2005), provide additional support to this model. In addition, it has also been proposed that ketamine is capable of increasing AMPA neurotransmission through suppression of spontaneous NMDAR-mediated neurotransmission that elicits a rapid eEF2- and BDNF-dependent potentiation mediated through increased surface expression of AMPA receptors (Autry et al, 2011; Nosyreva et al, 2013). Other studies demonstrate the requirement of BDNF/ TrkB-activation, showing that synaptogenic and behavioral actions of ketamine are blocked in mice with a knock-in of the BDNF Val-66-Met allele, and in conditional BDNF mutant mice (Autry et al, 2011; Liu et al, 2012). 


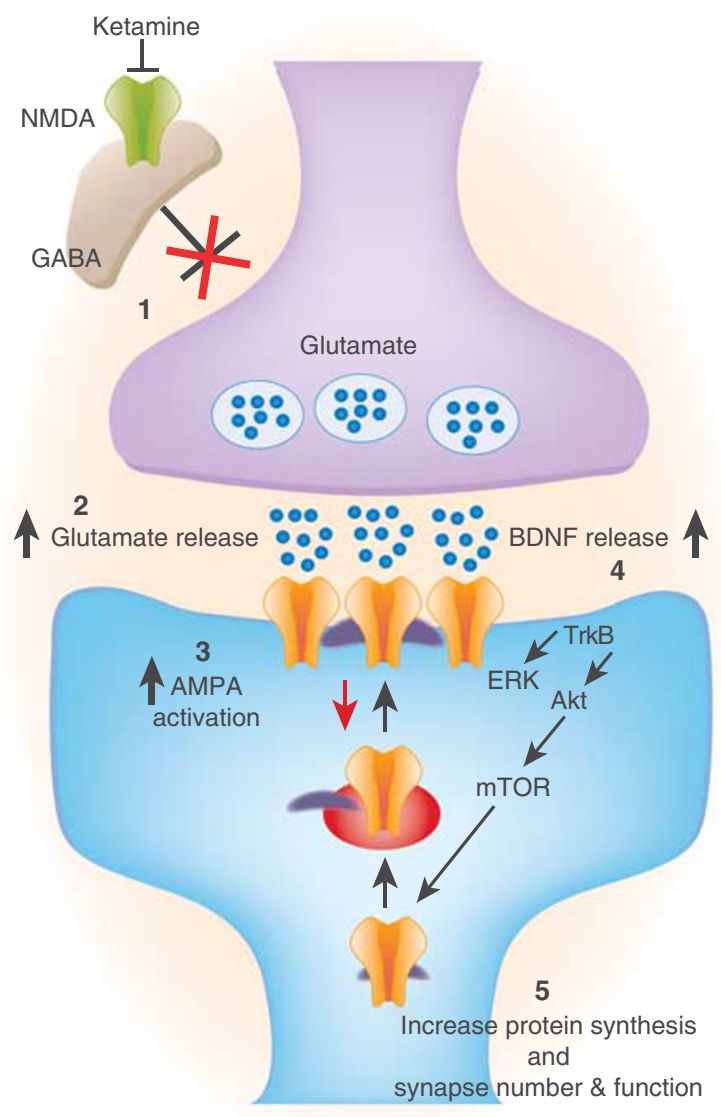

Figure I Proposed mechanism of ketamine's antidepressant action, whereby ketamine, through a blockade of tonic GABAergic inhibition (I), causes a surge in glutamate release and cycling (2). The resulting increased glutamatergic transmission through AMPA receptors (whose surface expression may be independently upregulated by the suppression of spontaneous NMDAR-mediated neurotransmission) (3) leads to increased BDNF-dependent (4) levels of synaptogenesis (5) that ultimately contribute to the rapid and sustained antidepressant effects.

Interestingly, a preliminary study found a lower rate of response to a ketamine treatment in met allele carriers (Laje et al, 2012).

The strong evidence of ketamine's rapid-onset antidepressant effects and emerging early evidence that other drugs targeting the glutamatergic system have antidepressant properties (Krystal et al, 2013), considered in the light of pathophysiological changes within the glutamatergic system that are associated with stress and psychopathology (Popoli et al, 2012), makes the glutamatergic system a highly attractive target for antidepressant drug development. However, the glutamatergic system is highly complex and there are still many unanswered questions surrounding the optimal means of modulating the system to provide safe, effective treatments for individuals suffering from mood and other neuropsychiatric disorders. Future studies will be required to determine if pharmacological factors such as trapping, half-life or selective action on subsets of NMDARs, moderate a drug's efficacy in the treatment of mood disorders.

\section{NMDA ANTAGONISM MAY NOT BE THE KEY MECHANISM OF ACTION FOR KETAMINE'S ANTIDEPRESSANT EFFECTS (ALAN F SCHATZBERG)}

That intravenous ketamine administration often causes an acute-but generally transient-improvement in mood in refractory depressed patients (Murrough et al, 2013a, b; Zarate et al, 2006a) has generated considerable excitement on the parts of clinicians and researchers, as well as industry who all hunger for rapidly effective new antidepressants. The putative MoA of antagonism of postsynaptic glutamatergic NMDA receptors, has led companies to attempt to develop other agents with similar MOA's in the hopes that the short-lived effects can be overcome and the side effects related to acute parenteral administration of ketamine can be avoided. To date, many of these strategies have not been effective-leaving some of us to argue that other MoA's may have a role and that some of these pose major problems for the field (Schatzberg, 2014). This perspective reviews evidence in support of the argument that ketamine's antidepressant properties reflect something other than NMDA antagonism, and discusses the possible consequences of misdirected development efforts.

\section{NMDA Antagonism and Glutamate as a Target}

Ketamine clearly antagonizes the NMDA receptor. That NMDA antagonism may be the key MoA underlying rapid antidepressant effects has led not only to much work on other NMDA antagonists but also on exploring other glutamatergic agents-eg, agonists or antagonists at linked glycine transporter sites on the NMDA receptor, agents that decrease synaptic glutamate concentrations, modulators of other glutamate receptors, etc. Animal data indicate that although ketamine is effective in animal models of antidepressant response, so too are agents that act essentially as agonists at the NMDA receptor (Burch, 2012; Huang et al, 2013). Contradictory data could be viewed as indicating the complex nature of glutamatergic function, but also that NMDA antagonism may not be ketamine's key MoA. To date, other NMDA antagonist strategies have not proven effective in man-some of which preceded recent ketamine excitement. For example, memantine is an NMDA antagonist that has not been shown to be effective in several depression studies (Sani et al, 2012; Smith et al, 2013; Zarate et al, 2006b). However, differences in half-lives and phosphorylation of eukaryotic elongation factor 2 and BDNF expression have been thought to have a role here (Gideons et al, 2014). Astra Zeneca's agent lanicemine (AZD6765) that traps synaptic glutamate was minimally effective in a single-dose pilot study (Zarate et al, 2013). However, thricea-week dosing over 3 weeks of lanicemine at $100 \mathrm{mg}$ per dose produced significant separation from placebo at weeks 2 and 3; $150 \mathrm{mg}$ produced separation at week 3 (Sanacora et al, 2013). More recently, in a larger scale, multi-center trial lanicemine at both $50 \mathrm{mg}$ and $100 \mathrm{mg}$ failed to separate from placebo (Sanacora et al, 2014). Another agent GLYX13 is a partial agonist for the glycine site such that it likely acts as an NMDA agonist. Intermediate doses have positive effects on mood without causing dissociation (Burch, 2012) and a recent press release on a Phase II-B trial reported that it produces longer-term responses with repeated 
administration (Naurex Press Release-6 May 2014). However, as of this writing, detailed data have not been presented that it is significantly more effective than placebo. A Taiwanese group recently reported that another glycine transporter inhibitor that acts essentially as an NMDA agonist was effective in animal models of antidepressant effects, and notably more effective than citalopram in depression (Huang et al, 2013). This is also supported by an Israeli study that augmenting antidepressant efficacy was possible via high doses of D-cycloserine, an NMDA agonist with potential antagonist properties as well (Heresco-Levy et al, 2013). Taken together, the data suggest that agonism at the NMDA receptor may be as, if not more, important than antagonism and that dissociation is not needed for a glutamate-mediated antidepressant effect.

Added to this web of glutamatergic confusion is the specter that we have been historically unsuccessful in our development of glutamatergic agents for major depression and schizophrenia. One notable strategy has been to focus on metabotropic glutamatergic (m-GLU) 2 or 3 receptors, and these have not been successful in either depression or schizophrenia. For example, an mGluR2 allosteric modulator recently failed to separate from placebo in anxious depression (Addex Press Release-7 February 2014) and others have not done well in Phase III trials in schizophrenia after showing initial promise (Patil et al, 2007; Stauffer et al, 2013). Thus, neither glutamate nor the NMDA receptor may be the key to further drug development. Of course, our field's recent poor track record of antidepressant development makes interpretation of the studies difficult.

One possible exception has to do with another postsynaptic glutamate receptor-AMPA - that can be activated by a putative marked increase in glutamate efflux secondary to ketamine (Duman and Aghajanian, 2012; Li et al, 2011; Maeng et al, 2008). As AMPA antagonists can block ketamine's pharmacological antidepressant properties in preclinical models including affecting mTOR (Duman and Aghajanian, 2012; see below), AMPA agonism could be a route for glutamatergic antidepressant development. Agonists are, however, historically difficult to develop for psychiatry because of potential tachyphylaxis; and, receptor potentiators are often partial agonists. The use of an antagonist for one receptor having an effect on another that are heterodimers or are colocalized has been hypothesized to occur for glucocorticoid antagonists' affecting mineralocorticoid receptor activity (Bachmann et al, 2003; Belanoff et al, 2002). To my knowledge, there are no data indicating antidepressant efficacy for AMPA agonists in man.

\section{Other MoA's}

Investigators have developed other hypotheses for ketamine's effects including second messenger effects on m-TOR (Li et al, 2011) that are shared with parenteral scopolamine, as well as release of brain-derived neurotropin factor (Autry et al, 2011). An intriguing putative MoA is ketamine's ability to stimulate sigma receptors, which appears to account for the drug's dissociation effects and may prove an important clue to how ketamine may be acting (Mori et al, 2012). Perhaps related, ketamine is a powerful mobilizer of midbrain catecholamines, particularly dopamine, and these properties could account for both the psychotomimetic and antidepressant properties (Tan et al, 2012). However, a recent rat study indicated that self-administration of d-amphetamine reinforces sigma 1 receptor agonist use that can be blocked by dopamine antagonists, whereas similar effects on sigma agonist use are not observed for ketamine (Hiranita et al, 2013). These data suggest that ketamine's antidepressant effects are independent of dopaminergic/sigma 1 interactions (Hiranita et al, 2013). Others have noted that ketamine may induce neuronal growth as well as be effective in a forced-swim test rat model, with the former not blocked by sigma receptor antagonists, although, the latter is-suggesting that the sigma receptor may have a role in some of ketamine's antidepressant effects (Robson et al, 2012). These studies do not address the putative role of sigma receptors in the dissociative properties of ketamine (Mori et al, 2012). Ketamine also potentiates the release of prefrontal serotonin (and perhaps other monoamines) through central nicotinic acetylcholine receptors (Nishitani et al, 2014).

The mTOR and stimulant-like properties may provide rationales for developing other antidepressants with similar pharmacologic effects and these could be pursued. However, stimulant-like properties may generate other worries for potential abuse (see below). Sigma receptor agents were targets of development more than a decade ago with some notable failures as well.

\section{Ketamine's Abuse Liability: Mu Opioid Receptor Effects}

There are a number of troubling findings regarding ketamine's pharmacology that should be given a thought. First, the drug does produce dissociation and psychosis and is subject to abuse. These suggest that potentially other systems may be affected. Second, ketamine does bind to mu, lambda and kappa opioid receptors. Preclinical studies indicate ketamine increases mu-opioid receptor densities in hippocampal tissue (Kekesi et al, 2011) and enhances mu opioid induced ERK1/2 phosphorylation in cell lines, as well as, speeds wait time for re-sensitizing ERK1/2 signaling (Gupta et al, 2011). Moreover, in anti-nocioception studies of ketamine in mice, analgesic effects were blocked by mu and lambda, but not by kappa, antagonists (Pacheco Dda et al, 2014). However, an earlier study did report that ketamine produced kappa-mediated disruption of cognition in rodents, suggestive of its dissociative properties in man (Nemeth et al, 2010). NMDA has a role in opioid-induced analgesia (Mion and Villevieille, 2013) and there are studies that point to ketamine's pain properties involving both opioid and NMDA receptors (Mehta et al, 2012). Taken together data do indicate that ketamine has agonistic effects on mu opioid receptors that do suggest a potential risk of abuse. However, rodent studies on reinforcing properties have been mixed. Intracranial self-stimulation appears not to be increased by the drug (Hillhouse et al, 2014); although, as others have pointed out, this does not eliminate the risk of abuse (Yang and Hashimoto, 2014) as choice preferencebased use can be increased with ketamine (Suzuki et al, 1999). (Ketamine has R and S enantiomers that also appear to differ in reinforcing effects.) Still recent data that the drug does seem to produce behavioral effects through binding to mu receptors provide a rather different framework 
for assessing its positive and negative pharmacological properties. Indeed, studies combining ketamine with the mu-antagonist naloxone in rodents and man, could be informative. Perhaps related to mu opioid effects are the observations that a positive family history of alcohol abuse is a predictor of ketamine antidepressant response (Luckenbaugh et al, 2012; Phelps et al, 2009).

\section{Is Understanding the MoA of Ketamine Important?}

One may wonder if and why knowing its MoA's are really important. If the drug is effective, why not just use it? For one, we have virtually no follow on treatments that are effective, and we need to understand the MoA if we are to develop both follow-on approaches, particularly orally administered agents. Otherwise, we may be left with repeated administration of an agent that could lead to dependence. The possible negative consequences are profound for patients, the public, and our profession. In fact if we step back for a moment and look at where we are-an intravenously administered agent that is a street drug of abuse, works rapidly and whose enantiomers are being studied by industry for intranasal use-we should be anxious. It may be that patients do not feel the exhilarated high of cocaine but they do experience dissociativeness often as part of a key predecessor to the transient mood elevating effects. Thus, we need to be as careful and conservative as possible and understand how it is acting and rule out the possibility of whether it acts as an opioid. Indeed, as I recently pointed out elsewhere (Schatzberg, 2014) the report of Rodriguez et al (2013) of intravenous ketamine being effective in obsessive compulsive patients parallels the observations of Koran et al (2005) that oral morphine was also effective in patients with the disorder.

A related reason why we need to understand the MoA better is that biotech and pharmaceutical companies base development strategies on putative MoA's and an emphasis on NMDA may lead to over emphasis on glutamate and NMDA antagonism at the expense of other mechanisms. The competition for dollars invested will mean the loss of other opportunities. If the MoA involves opioid receptor agonism, we as a field can openly discuss and perhaps debate the wisdom of pursuing this approach. Indeed, one company-Alkermes-has announced positive Phase II results of a combination of an agonist and antagonist to provide antidepressant relief and to minimize tolerance and abuse (Alkermes Press release-April 2013). Employing mu agonists as antidepressants-whether they are ketamine or others-will require an open dialog about the risk/benefit of such approaches.

\section{HOW TO MOVE THE FIELD FORWARD (GERARD SANACORA AND ALAN F SCHATZBERG)}

Ultimately the primary goal for the field is to provide safe, effective treatment options to people suffering with mood disorders. In line with this goal, how can we build on the findings showing ketamine to produce a rapid transient antidepressant effect?

The first step is to clearly establish the true clinical efficacy, effectiveness, and safety of ketamine through additional well-controlled and monitored clinical trials. Showing clinically meaningful short-term improvement (such as decreased risks of suicidal behavior, decreased hospital admission rates or lengths of stay) and/or sustainable response lasting more than a few weeks is essential in proving true clinical utility. On the basis of reports of ketamine's rapid effects on suicidal ideation (DiazGranados et al, 2010; Price et al, 2014), several controlled studies are currently underway examining the short-term clinical benefits of ketamine in crisis settings such as in the emergency department with suicidal patients. The results from these studies will begin to provide us with information related to the actual clinical utility of ketamine as a crisis intervention. Although several case series have suggested long-term effects of repeated administration, the first placebo-controlled data demonstrating sustained effects with repeated dosing was only recently presented (Singh, 2014). However, the functional unblinding associated with ketamine at this dose continues to cloud the interpretation of the studies, especially considering the fact that the dissociative properties of ketamine have been shown to be a significant predictor of response (Luckenbaugh et al, 2014). In the comparison trial of ketamine $v s$ midazolam (Murrough et al, 2013a), dissociation was twice as likely to occur in ketamine-treated patients than in those treated with the benzodiazepine (60 vs 30\%). To fully control for the placebo response, an improved 'active placebo' with greater dissociative effects would be optimal. Alternatively, a soon-to-start multicenter NIMH-sponsored trial exploring the dose-response relationship for ketamine may allow for better comparison with midazolam as a control. One strategy might be to find a higher dose of midazolam that could produce higher rates of, and perhaps more intense, dissociative symptoms that could provide a better control for this side reaction, and preserve the blind. Another alternative might be to use an agent that has dissociative properties as a control, although, some of these may be other drugs of abuse. (As discussed below, given the possible opioid properties of ketamine, a comparison trial with an opioid such as parenteral morphine would be of interest as well.)

The second step is to optimize the safety of the treatment approach, either improving the delivery of ketamine itself, or through the development of novel medications that share ketamine's critical mechanisms of antidepressant action but have improved safety profiles.

Several factors currently limit the broader use of ketamine in the treatment of mood disorders. Although serious adverse events are relatively rare, acute risks of ketamine treatment include cardiovascular effects such as elevated blood pressure and heart rate, and psychological emergence events (Strayer and Nelson, 2008). Single administration of sub-anesthetic doses of ketamine, such as those primarily used in the existing proof-of-concept studies appear to have a very low risk of serious adverse events (Perry et al, 2007), but rare transient episodes of hypotension and bradycardia have been observed in depressed patients (McGirr et al, 2014). Of potentially greater concern are the relatively unknown risks of repeated administration. Studies examining ketamine abusers and rodent models suggest that repeated ketamine exposure can have deleterious effects on brain structure and function under certain conditions 
(age of exposure, dose, and duration; Liao et al, 2011; Schobel et al, 2013; Wang et al, 2013). However, the limited studies involving repeated dosing of mood disorder patients, report that the treatment has been generally well tolerated, and there have been no reports raising the level of concern related to cognitive difficulties for mood-disordered patients (aan het Rot et al, 2010; Blier et al, 2012; Shiroma et al, 2014). The known risk of urinary cystitisassociated repeated ketamine administration appears to be associated with very high levels of use for prolonged periods (Tam et al, 2014; Wood, 2013), but it remains as another concern that needs to be considered with longer-term treatment strategies. Moreover, ketamine is known to be a drug of abuse, raising the additional concerns that repeated administration of the drug could have a liability for drug abuse. These potential complications, although not necessarily ruling out future development of ketamine for broader clinical use, are clearly going to require closer long-term follow-up in controlled studies if the drug is going to be used with any regularity in the clinics. It remains to be seen whether the use of the selective S-enantiomer of ketamine, which appears to have similar antidepressant effects (Segmiller et al, 2013) also carries the same level of risk.

Identifying factors that could improve the risk benefit ratio is one way to mitigate the risks of ketamine exposure. Findings that family history of alcoholism is a significant predictor of ketamine response (Luckenbaugh et al, 2012; Phelps et al, 2009) suggest one potential group with an enhanced likelihood of benefit but may also suggest that the drug's pharmacologic actions may be closer to those of abuse than one might want. There are a number of studies that could be undertaken to assess risk. For one, abuse liability studies could be conducted in depressed patients, casual drug users, and healthy controls. These studies would involve blinded comparisons of ketamine and other agents of abuse with the rating of subjective experiences, including blinded self-assessment of acute and longer subjective effects and placing monetary values on different compounds. Enhanced risk of psychosis could be studied by perhaps applying a biological test such as sensory gating as a predictor of psychotic response, and combining it with assessments of personal and family history. This might yield a useable test battery for the field. Finally, pharmacogenetic markers, such as the val-66-met BDNF SNP mentioned above, could be especially useful if the effects can be replicated and shown to be meaningfully predictive.

\section{Novel Drug Development}

Understanding the MoA is important to provide clues for the development of alternative glutamatergic agents that might produce similar benefits with greater convenience (eg, route of administration), better longer-term efficacy, fewer and less severe side effects, and/or reduced longerterm risk. As outlined above, there is some disagreement on what mechanisms are most likely underlying ketamine's antidepressant effects. Dr Sanacora maintains the hypothesis that ketamine's effects on glutamatergic neurotransmission are critical in initiating a cascade of events that ultimately facilitate an antidepressant response, whereas Dr Schatzberg suggests that other, non-glutamateric systems, may be having the critical role in the drug's mechanism of action. These distinct positions on the mechanism of action arise largely from differences in the interpretation of the existing data. Do the preclinical studies demonstrate glutamatergic modulation is necessary for ketamine to have effects on mood? Do the existing clinical studies show other NMDAR antagonists to have efficacy? Could alternative MoAs account for ketamine's mood effects? However, we both agree that it is best to keep an open mind when evaluating the underlying mechanisms of action related to ketamine's unique antidepressant effects. In addition to ketamine's effects on the glutamatergic system, there is increasing evidence that ketamine has effects on the opioid system (Gupta et al, 2011), inflammation (Walker et al, 2013), and yes even the monoaminergic systems (Belujon and Grace, 2014; Fukumoto et al, 2014) that could be critical in generating the antidepressant response. Until more definitive studies are completed at both the clinical and preclinical levels, it is wise to consider all options.

To examine the antidepressant mechanism of action, it will be important to develop and validate clear measures of target engagement. As there are no readily available ligands for the NMDAR to allow PET imaging studies, alternative measures are needed. A recent paper suggests that it may be possible to indirectly monitor ketamine's effects with the use of a PET ligand, $\left[{ }^{11} \mathrm{C}\right] \mathrm{ABP} 688$ (E)-3-[2-(6-methyl-2pyridinyl)ethynyl]-2-cyclohexen-1-one-O-(methyl- $\left.{ }_{11} \mathrm{C}\right)$ oxime, that has high affinity for the mGluR5 receptor, which is sensitive to changes in endogenous glutamate (DeLorenzo et al, 2014). Preclinical and small clinical studies suggest other imaging methods, such as ${ }^{13} \mathrm{C}$-MRS measures of glutamate cycling (Chowdhury et al, 2012), or fMRI studies of brain network connectivity could be used to evaluate target engagement, and perhaps may even be more closely related to the critical downstream mechanisms generating the antidepressant response (Dawson et al, 2014; Driesen et al, 2013). Other recent studies also suggest that EEG measures could be used to detect NMDAR target engagement (Hong et al, 2010; Kocsis et al, 2013), a tool that may actually be useful in determining clinical dosing (Sanacora et al, 2013). To explore the effects of ketamine on the opioid system, one could use PET to explore mu opioid binding pre- and post-ketamine in either patients or controls. Mu antagonists such as naloxone could be used to attempt to block the antidepressant effects in animal models, as well as in patients. Similarly, kappa and lambda antagonists could also be applied.

In sum, we remain in disagreement over what we have learned from our experience with ketamine and another NMDAR drugs to date for the treatment of mood disorders. We agree that there is clear evidence that ketamine can produce rapid transient antidepressant-like effects, but remain divergent in our opinions on the mechanisms mediating these effects and the potential to act on what we know to initiate novel treatment approaches or suggest novel pathways for drug development. We agree that it is premature to conclude that any single mechanism is solely responsible for the antidepressant response, and that the response is potentially mediated through complex pathways downstream from ketamine's direct actions at any receptor. We strongly agree that preclinical studies should explore 
potential alternative MoAs and that more clinical studies are needed to clearly establish the true clinical effectiveness and safety of the treatment before it is made widely available in the clinical setting.

\section{FUNDING AND DISCLOSURE}

Dr Sanacora has received consulting fees form AstraZeneca, Avanier Pharmaceuticals, Bristol-Myers Squibb, Eli Lilly, Hoffman La-Roche, Merck, Naurex, Noven Pharmaceuticals ${ }^{\star}$, and Takeda over the last 24 months. He has also received additional research contracts from AstraZeneca, BristolMyers Squibb, Eli Lilly, Johnson \& Johnson, Hoffman La-Roche, Merck, Naurex and Servier over the last 24 months. Free medication was provided to Dr Sanacora for an NIH sponsored study by Sanofi-Aventis. In addition, he holds shares in BioHaven Pharmaceuticals Holding Company and is a co-inventor on a US patent (\#8778979) related to the use of glutamatergic drugs in the treatment of neuropsychiatric disorders held by Yale University. Dr Schatzberg has served as a consultant to Bay City Capital, BrainCells, CeNeRx, Cervel, Depomed, Eli Lilly, Genentech, Gilead, Jazz, Lundbeck/ Takeda, McKinsey, Merck*, MSI, Naurex, Neuronetics, Novadel, Pfizer*, PharmaNeuroBoost*, Sunovion, Synosia, and Xhale*. Dr Schatzberg has had equity in Amnestix, BrainCells, CeNeRx, Cervel, Corcept ${ }^{\star}$ (co-founder), Delpor, Forest Labs, Merck*, Neurocrine*, Novadel, Pfizer*, PharmaNeuroBoost, Seattle Genetics*, Somaxon, Synosia, Titan, and $\mathrm{Xhale}^{*}$. He is a named inventor on pharmacogenetic use patents on glucocorticoid antagonists and on prediction of antidepressant response. Dr Schatzberg has also received speaking fees in the past from Merck ${ }^{\star}{ }^{\star}$ Greater than $\$ 10000 /$ year in income or current equity value.

\section{ACKNOWLEDGEMENTS}

R01 MH081211 (GS) and the Pritzker Family Foundation (AFS).

\section{BLOG COMMENTS}

For discussion of this Circumspective, go to http://www. acnp.org/resources/acnpblog.aspx.

\section{REFERENCES}

aan het Rot M, Collins KA, Murrough JW, Perez AM, Reich DL, Charney DS et al (2010). Safety and efficacy of repeated-dose intravenous ketamine for treatment-resistant depression. Biol Psychiatry 67: 139-145.

Aan Het Rot M, Zarate CA Jr, Charney DS, Mathew SJ (2012). Ketamine for depression: where do we go from here? Biol Psychiatry 72: 537-547.

Anis NA, Berry SC, Burton NR, Lodge D (1983). The dissociative anaesthetics, ketamine and phencyclidine, selectively reduce excitation of central mammalian neurones by N-methylaspartate. $\mathrm{Br}$ J Pharmacol 79: 565-575.

Autry AE, Adachi M, Nosyreva E, Na ES, Los MF, Cheng PF et al (2011). NMDA receptor blockade at rest triggers rapid behavioural antidepressant responses. Nature 475: 91-95.

Bachmann CG, Linthorst AC, Holsboer F, Reul JM (2003). Effect of chronic administration of selective glucocorticoid receptor antagonists on the rat hypothalamic-pituitary-adrenocortical axis. Neuropsychopharmacology 28: 1056-1067.

Belanoff JK, Rothschild AJ, Cassidy F, DeBattista C, Baulieu EE, Schold C et al (2002). An open label trial of C-1073 (mifepristone) for psychotic major depression. Biol Psychiatry 52: 386-392.

Belujon P, Grace AA (2014). Restoring mood balance in depression: ketamine reverses deficit in dopamine-dependent synaptic plasticity. Biol Psychiatry (e-pub ahead of print).

Bergman SA (1999). Ketamine: review of its pharmacology and its use in pediatric anesthesia. Anesth Prog 46: 10-20.

Blier P, Zigman D, Blier J (2012). On the safety and benefits of repeated intravenous injections of ketamine for depression. Biol Psychiatry 72: e11-e12.

Burch R (2012): A phase 2, randomized single blind, single intravenous dose of GLYX-12, an NMDA receptor glycine site functional partial agonist, in subjects with major depressive disorder with inadequate response to antidepressant medication. 51st Annual Meeting, American College of Neuropyschopharmacology, 2012; Hollywood, FL, USA.

Chowdhury GM, Behar KL, Cho W, Thomas MA, Rothman DL, Sanacora G (2012). (1)H-[(1)(3)C]-nuclear magnetic resonance spectroscopy measures of ketamine's effect on amino acid neurotransmitter metabolism. Biol Psychiatry 71: 1022-1025.

Dawson N, McDonald M, Higham DJ, Morris BJ, Pratt JA (2014). Subanesthetic ketamine treatment promotes abnormal interactions between neural subsystems and alters the properties of functional brain networks. Neuropsychopharmacology 39: 1786-1798.

DeLorenzo C, DellaGioia N, Bloch M, Sanacora G, Nabulsi N, Abdallah $C$ et al (2014). In vivo ketamine-induced changes in [C]ABP688 binding to metabotropic glutamate receptor subtype 5. Biol Psychiatry (e-pub ahead of print).

DiazGranados N, Ibrahim LA, Brutsche NE, Ameli R, Henter ID, Luckenbaugh DA et al (2010). Rapid resolution of suicidal ideation after a single infusion of an N-methyl-D-aspartate antagonist in patients with treatment-resistant major depressive disorder. J Clin Psychiatry 71: 1605-1611.

Driesen NR, McCarthy G, Bhagwagar Z, Bloch M, Calhoun V, D’Souza DC et al (2013). Relationship of resting brain hyperconnectivity and schizophrenia-like symptoms produced by the NMDA receptor antagonist ketamine in humans. Mol Psychiatry 18: 1199-1204.

Duman RS, Aghajanian GK (2012). Synaptic dysfunction in depression: potential therapeutic targets. Science 338: 68-72.

Dwyer JM, Lepack AE, Duman RS (2012). mTOR activation is required for the antidepressant effects of $\operatorname{mGluR}(2) /(3)$ blockade. Int J Neuropsychopharmacol 15: 429-434.

Emnett CM, Eisenman LN, Taylor AM, Izumi Y, Zorumski CF, Mennerick S (2013). Indistinguishable synaptic pharmacodynamics of the N-methyl-D-aspartate receptor channel blockers memantine and ketamine. Mol Pharmacol 84: 935-947.

Fukumoto K, Iijima M, Chaki S (2014). Serotonin-1A receptor stimulation mediates effects of a metabotropic glutamate $2 / 3$ receptor antagonist, 2S-2-amino-2-(1S,2S-2-carboxycycloprop-1yl)-3-(xanth-9-yl)propanoic acid (LY341495), and an N-methyl-Daspartate receptor antagonist, ketamine, in the novelty-suppressed feeding test. Psychopharmacology 231: 2291-2298.

Gideons ES, Kavalali ET, Monteggia LM (2014). Mechanisms underlying differential effectiveness of memantine and ketamine in rapid antidepressant responses. Proc Natl Acad Sci USA 111: 8649-8654.

Gupta A, Devi LA, Gomes I (2011). Potentiation of mu-opioid receptormediated signaling by ketamine. J Neurochem 119: 294-302.

Hardingham GE, Bading H (2010). Synaptic versus extrasynaptic NMDA receptor signalling: implications for neurodegenerative disorders. Nat Rev Neurosci 11: 682-696.

Heresco-Levy U, Gelfin G, Bloch B, Levin R, Edelman S, Javitt DC et al (2013). A randomized add-on trial of high-dose D-cycloserine for treatment-resistant depression. Int J Neuropsychopharmacol 16: 501-506. 
Hillhouse TM, Porter JH, Negus SS (2014). Dissociable effects of the noncompetitive NMDA receptor antagonists ketamine and MK-801 on intracranial self-stimulation in rats. Psychopharmacology 231: 2705-2716.

Hiranita T, Soto PL, Tanda G, Kopajtic TA, Katz JL (2013). Stimulants as specific inducers of dopamine-independent sigma agonist self-administration in rats. J Pharmacol Exp Ther 347: 20-29.

Hong LE, Summerfelt A, Buchanan RW, O’Donnell P, Thaker GK, Weiler MA et al (2010). Gamma and delta neural oscillations and association with clinical symptoms under subanesthetic ketamine. Neuropsychopharmacology 35: 632-640.

Huang CC, Wei IH, Huang CL, Chen KT, Tsai MH, Tsai P et al (2013). Inhibition of glycine transporter-I as a novel mechanism for the treatment of depression. Biol Psychiatry 74: 734-741.

Iovieno N, Papakostas GI (2012). Correlation between different levels of placebo response rate and clinical trial outcome in major depressive disorder: a meta-analysis. J Clin Psychiatry 73: 1300-1306.

Karasawa J, Shimazaki T, Kawashima N, Chaki S (2005). AMPA receptor stimulation mediates the antidepressant-like effect of a group II metabotropic glutamate receptor antagonist. Brain Res 1042: 92-98.

Kekesi O, Tuboly G, Szucs M, Birkas E, Morvay Z, Benedek G et al (2011). Long-lasting, distinct changes in central opioid receptor and urinary bladder functions in models of schizophrenia in rats. Eur J Pharmacol 661: 35-41.

Kocsis B, Brown RE, McCarley RW, Hajos M (2013). Impact of ketamine on neuronal network dynamics: translational modeling of schizophrenia-relevant deficits. CNS Neurosci Ther 19: 437-447.

Koike H, Iijima M, Chaki S (2011). Involvement of AMPA receptor in both the rapid and sustained antidepressant-like effects of ketamine in animal models of depression. Behav Brain Res 224: 107-111.

Koran LM, Aboujaoude E, Bullock KD, Franz B, Gamel N, Elliott M (2005). Double-blind treatment with oral morphine in treatment-resistant obsessive-compulsive disorder. J Clin Psychiatry 66: 353-359.

Kotermanski SE, Wood JT, Johnson JW (2009). Memantine binding to a superficial site on NMDA receptors contributes to partial trapping. J Physiol 587(Pt 19): 4589-4604.

Krystal JH, Sanacora G, Duman RS (2013). Rapid-acting glutamatergic antidepressants: the path to ketamine and beyond. Biol Psychiatry 73: 1133-1141.

Laje G, Lally N, Mathews D, Brutsche N, Chemerinski A, Akula N et al (2012). Brain-derived neurotrophic factor Val66Met polymorphism and antidepressant efficacy of ketamine in depressed patients. Biol Psychiatry 72: e27-e28.

Li N, Lee B, Liu RJ, Banasr M, Dwyer JM, Iwata M et al (2010). mTOR-dependent synapse formation underlies the rapid antidepressant effects of NMDA antagonists. Science 329: 959-964.

Li N, Liu RJ, Dwyer JM, Banasr M, Lee B, Son H et al (2011). Glutamate N-methyl-D-aspartate receptor antagonists rapidly reverse behavioral and synaptic deficits caused by chronic stress exposure. Biol Psychiatry 69: 754-761.

Liao Y, Tang J, Corlett PR, Wang X, Yang M, Chen H et al (2011). Reduced dorsal prefrontal gray matter after chronic ketamine use. Biol Psychiatry 69: 42-48.

Lima-Ojeda JM, Vogt MA, Pfeiffer N, Dormann C, Kohr G, Sprengel R et al (2013). Pharmacological blockade of GluN2Bcontaining NMDA receptors induces antidepressant-like effects lacking psychotomimetic action and neurotoxicity in the perinatal and adult rodent brain. Prog Neuropsychopharmacol Biol Psychiatry 45: 28-33.

Liu RJ, Lee FS, Li XY, Bambico F, Duman RS, Aghajanian GK (2012). Brain-derived neurotrophic factor Val66Met allele impairs basal and ketamine-stimulated synaptogenesis in prefrontal cortex. Biol Psychiatry 71: 996-1005.

Luckenbaugh DA, Ibrahim L, Brutsche N, Franco-Chaves J, Mathews D, Marquardt CA et al (2012). Family history of alcohol dependence and antidepressant response to an $\mathrm{N}$-methyl-D-aspartate antagonist in bipolar depression. Bipolar Disord 14: 880-887.

Luckenbaugh DA, Niciu MJ, Ionescu DF, Nolan NM, Richards EM, Brutsche NE et al (2014). Do the dissociative side effects of ketamine mediate its antidepressant effects? J Affect Disord 159: 56-61.

Maeng S, Zarate CA Jr., Du J, Schloesser RJ, McCammon J, Chen G et al (2008). Cellular mechanisms underlying the antidepressant effects of ketamine: role of alpha-amino-3-hydroxy-5-methylisoxazole-4-propionic acid receptors. Biol Psychiatry 63: 349-352.

McGirr A, Berlim MT, Bond DJ, Fleck MP, Yatham LN, Lam RW (2014). A systematic review and meta-analysis of randomized, double-blind, placebo-controlled trials of ketamine in the rapid treatment of major depressive episodes. Psychol Med 10: 1-12.

Mehta AK, Halder S, Khanna N, Tandon OP, Sharma KK (2012). Antagonism of stimulation-produced analgesia by naloxone and $\mathrm{N}$-methyl-D-aspartate: role of opioid and N-methyl-D-aspartate receptors. Hum Exp Toxicol 31: 51-56.

Mion G, Villevieille T (2013). Ketamine pharmacology: an update (pharmacodynamics and molecular aspects, recent findings). CNS Neurosci Ther 19: 370-380.

Moghaddam B, Adams B, Verma A, Daly D (1997). Activation of glutamatergic neurotransmission by ketamine: a novel step in the pathway from NMDA receptor blockade to dopaminergic and cognitive disruptions associated with the prefrontal cortex. J Neurosci 17: 2921-2927.

Mori T, Yoshizawa K, Shibasaki M, Suzuki T (2012). Discriminative stimulus effects of hallucinogenic drugs: a possible relation to reinforcing and aversive effects. J Pharmacol Sci 120: 70-76.

Murrough JW, Iosifescu DV, Chang LC, Al Jurdi RK, Green CE, Perez AM et al (2013a). Antidepressant efficacy of ketamine in treatment-resistant major depression: a two-site randomized controlled trial. Am J Psychiatry 170: 1134-1142.

Murrough JW, Perez AM, Pillemer S, Stern J, Parides MK, aan het Rot $M$ et al (2013b). Rapid and longer-term antidepressant effects of repeated ketamine infusions in treatment-resistant major depression. Biol Psychiatry 74: 250-256.

Nemeth CL, Paine TA, Rittiner JE, Beguin C, Carroll FI, Roth BL et al (2010). Role of kappa-opioid receptors in the effects of salvinorin A and ketamine on attention in rats. Psychopharmacology 210: 263-274.

Nishitani N, Nagayasu K, Asaoka N, Yamashiro M, Shirakawa H, Nakagawa $\mathrm{T}$ et al (2014). Raphe AMPA receptors and nicotinic acetylcholine receptors mediate ketamine-induced serotonin release in the rat prefrontal cortex. Int J Neuropsychopharmacology 17: 1321-1326.

Nosyreva E, Szabla K, Autry AE, Ryazanov AG, Monteggia LM, Kavalali ET (2013). Acute suppression of spontaneous neurotransmission drives synaptic potentiation. J Neurosci 33: 6990-7002.

Nowak G, Ordway GA, Paul IA (1995). Alterations in the N-methylD-aspartate (NMDA) receptor complex in the frontal cortex of suicide victims. Brain Res 675: 157-164.

Nowak G, Ossowska G, Jopek R, Papp M (1998). Strychnineinsensitive glycine/NMDA sites are altered in two stress models of depression. Pol J Pharmacol 50: 365-369.

Nowak G, Trullas R, Layer RT, Skolnick P, Paul IA (1993). Adaptive changes in the N-methyl-D-aspartate receptor complex after chronic treatment with imipramine and 1-aminocyclopropanecarboxylic acid. J Pharmacol Exp Ther 265: 1380-1386.

Pacheco Dda F, Romero TR, Duarte ID (2014). Central antinociception induced by ketamine is mediated by endogenous opioids and mu- and delta-opioid receptors. Brain Res 1562: 69-75.

Papp M, Moryl E (1994). Antidepressant activity of non-competitive and competitive NMDA receptor antagonists in a chronic mild stress model of depression. Eur J Pharmacol 263: 1-7.

Parsons MP, Raymond LA (2014). Extrasynaptic NMDA receptor involvement in central nervous system disorders. Neuron 82: 279-293. 
Patil ST, Zhang L, Martenyi F, Lowe SL, Jackson KA, Andreev BV et al (2007). Activation of mGlu2/3 receptors as a new approach to treat schizophrenia: a randomized Phase 2 clinical trial. Nat Med 13: 1102-1107.

Paul IA, Layer RT, Skolnick P, Nowak G (1993). Adaptation of the NMDA receptor in rat cortex following chronic electroconvulsive shock or imipramine. Eur J Pharmacol 247: 305-311.

Perry EB Jr, Cramer JA, Cho HS, Petrakis IL, Karper LP, Genovese A et al (2007). Psychiatric safety of ketamine in psychopharmacology research. Psychopharmacology 192: 253-260.

Phelps LE, Brutsche N, Moral JR, Luckenbaugh DA, Manji HK, Zarate CA Jr (2009). Family history of alcohol dependence and initial antidepressant response to an N-methyl-D-aspartate antagonist. Biol Psychiatry 65: 181-184.

Pilc A, Wieronska JM, Skolnick P (2013). Glutamate-based antidepressants: preclinical psychopharmacology. Biol Psychiatry 73: 1125-1132.

Popoli M, Yan Z, McEwen BS, Sanacora G (2012). The stressed synapse: the impact of stress and glucocorticoids on glutamate transmission. Nat Rev Neurosci 13: 22-37.

Preskorn SH, Baker B, Kolluri S, Menniti FS, Krams M, Landen JW (2008). An innovative design to establish proof of concept of the antidepressant effects of the NR2B subunit selective N-methylD-aspartate antagonist, CP-101606, in patients with treatmentrefractory major depressive disorder. J Clin Psychopharmacol 28: 631-637.

Price RB, Iosifescu DV, Murrough JW, Chang LC, Al Jurdi RK, Iqbal SZ et al (2014). Effects of ketamine on explicit and implicit suicidal cognition: a randomized controlled trial in treatmentresistant depression. Depress Anxiety 31: 335-343.

Robson MJ, Elliott M, Seminerio MJ, Matsumoto RR (2012). Evaluation of sigma (sigma) receptors in the antidepressant-like effects of ketamine in vitro and in vivo. Eur Neuropsychopharmacol 22: 308-317.

Rodriguez CI, Kegeles LS, Levinson A, Feng T, Marcus SM, Vermes $\mathrm{D}$ et al (2013). Randomized controlled crossover trial of ketamine in obsessive-compulsive disorder: proof-of-concept. Neuropsychopharmacology 38: 2475-2483.

Sanacora G, Johnson M, Khan A, Atkinson S, Riesenberg R, Schronen J et al (2014): Adjunctive lanicemine (AZD6765) in patients with major depressive disorder and a history of inadequate response to antidepressants: primary results from a randomized, placebocontrolled study (PURSUIT). Presented at the American Society of Clinical Psychiatry; Hollywood, FL, USA.

Sanacora G, Smith MA, Pathak S, Su HL, Boeijinga PH, McCarthy DJ et al (2013). Lanicemine: a low-trapping NMDA channel blocker produces sustained antidepressant efficacy with minimal psychotomimetic adverse effects. Mol Psychiatry 19: 978-985.

Sani G, Serra G, Kotzalidis GD, Romano S, Tamorri SM, Manfredi $\mathrm{G}$ et al (2012). The role of memantine in the treatment of psychiatric disorders other than the dementias: a review of current preclinical and clinical evidence. CNS Drugs 26: 663-690.

Schatzberg AF (2014). A word to the wise about ketamine. Am J Psychiatry 171: 262-264.

Schobel SA, Chaudhury NH, Khan UA, Paniagua B, Styner MA, Asllani I et al (2013). Imaging patients with psychosis and a mouse model establishes a spreading pattern of hippocampal dysfunction and implicates glutamate as a driver. Neuron 78: 81-93.

Segmiller F, Ruther T, Linhardt A, Padberg F, Berger M, Pogarell O et al (2013). Repeated S-ketamine infusions in therapy resistant depression: a case series. J Clin Pharmacol 53: 996-998.

Shiroma PR, Albott CS, Johns B, Thuras P, Wels J, Lim KO (2014). Neurocognitive performance and serial intravenous subanesthetic ketamine in treatment-resistant depression. Int J Neuropsychopharmacol 17: 1805-1813.
Singh J (2014): A double-blind, randomized, placebo-controlled, parallel group, dose frequency study of intravenous ketamine in patients with treatment-resistant depression. Presented at the American Society for Clinical Psychopharmacology. Hollywood, FL, USA.

Sinner B, Graf BM (2008). Ketamine. Handb Exp Pharmacol 313-333.

Skolnick P (1999). Antidepressants for the new millennium. Eur J Pharmacol 375: 31-40.

Smith EG, Deligiannidis KM, Ulbricht CM, Landolin CS, Patel JK, Rothschild AJ (2013). Antidepressant augmentation using the $\mathrm{N}$-methyl-D-aspartate antagonist memantine: a randomized, double-blind, placebo-controlled trial. J Clin Psychiatry 74: 966-973.

Stauffer VL, Millen BA, Andersen S, Kinon BJ, Lagrandeur L, Lindenmayer JP et al (2013). Pomaglumetad methionil: no significant difference as an adjunctive treatment for patients with prominent negative symptoms of schizophrenia compared to placebo. Schizophr Res 150: 434-441.

Strayer RJ, Nelson LS (2008). Adverse events associated with ketamine for procedural sedation in adults. Am J Emer Med 26: 985-1028.

Suzuki T, Aoki T, Kato H, Yamazaki M, Misawa M (1999). Effects of the 5-HT(3) receptor antagonist ondansetron on the ketamine- and dizocilpine-induced place preferences in mice. Eur J Pharmacol 385: 99-102.

Tam YH, Ng CF, Pang KK, Yee CH, Chu WC, Leung VY et al (2014). One-stop clinic for ketamine-associated uropathy: report on service delivery model, patients' characteristics and noninvasive investigations at baseline by a cross-sectional study in a prospective cohort of 318 teenagers and young adults. BJU Int (e-pub ahead of print).

Tan S, Lam WP, Wai MS, Yu WH, Yew DT (2012). Chronic ketamine administration modulates midbrain dopamine system in mice. PLoS One 7: e43947.

Thomson AM, West DC, Lodge D (1985). An N-methylaspartate receptor-mediated synapse in rat cerebral cortex: a site of action of ketamine? Nature 313: 479-481.

Walker AK, Budac DP, Bisulco S, Lee AW, Smith RA, Beenders B et al (2013). NMDA receptor blockade by ketamine abrogates lipopolysaccharide-induced depressive-like behavior in C57BL/ 6J mice. Neuropsychopharmacology 38: 1609-1616.

Wang C, Zheng D, Xu J, Lam W, Yew DT (2013). Brain damages in ketamine addicts as revealed by magnetic resonance imaging. Front Neuroanat 7: 23.

Wood D (2013). Ketamine and damage to the urinary tract. Addiction 108: 1515-1516.

Yang C, Hashimoto K (2014). Rapid antidepressant effects and abuse liability of ketamine. Psychopharmacology 231: 2041-2042.

Zarate CA Jr., Mathews D, Ibrahim L, Chaves JF, Marquardt C, Ukoh I et al (2013). A randomized trial of a low-trapping nonselective N-methyl-D-aspartate channel blocker in major depression. Biol Psychiatry 74: 257-264.

Zarate CA Jr., Singh JB, Carlson PJ, Brutsche NE, Ameli R, Luckenbaugh DA et al (2006a). A randomized trial of an $\mathrm{N}$-methyl-D-aspartate antagonist in treatment-resistant major depression. Arch Gen Psychiatry 63: 856-864.

Zarate CA Jr., Singh JB, Quiroz JA, De Jesus G, Denicoff KK, Luckenbaugh DA et al (2006b). A double-blind, placebocontrolled study of memantine in the treatment of major depression. Am J Psychiatry 163: 153-155.

Zhou X, Ding Q, Chen Z, Yun H, Wang H (2013). Involvement of the GluN2A and GluN2B subunits in synaptic and extrasynaptic $\mathrm{N}$-methyl-D-aspartate receptor function and neuronal excitotoxicity. J Biol Chem 288: 24151-24159. 